\title{
. LIFE IN THE CLINICAL SENATE: PART 3
}

\section{In her final column, Elizabeth Gonzalez-Malaga talks us through the challenges of the post and being prepared for the next steps.}

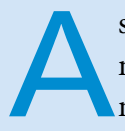
s our lives get busier and busier, we might live our day in fast forward mode. When we get involved in many projects, we may not be aware of the learning outcomes brought by each of them; we forget to embrace our achievements and new opportunities. Towards the end of my Fellowship, we were asked to prepare a final presentation about our involvement in Clinical Senate projects and the impact they had within our development. Creating those slides made me realise the large effect that this twelve-month programme had towards my professional and personal growth.

From my surnames you might have already notice that I am Spanish. Having lived in the UK for over a decade, my spoken and written English has gradually improved. However, the Clinical Senate Fellowship gave me the last push to grow my confidence when speaking to larger audiences, particularly non-dental; this is crucial as we advocate for the integration of dentistry within patients' general health care and wellbeing. I do not think the butterflies in my stomach before public speaking will ever disappear, however, I realised that the more you do it the better you get. While practice makes perfection, having additional tools help. During my fellowship, I attended a Media Training Course organised by the East Midlands NHS Clinical Senate for their Council Members. The main aim of this one-day event was to learn how to handle the broadcast media (TV and radio); learning the dos and don'ts for a successful interview. Preparation and rehearsal are the two key elements for a successful performance; this can be applied to job interviews, presentations and oral exams. At the end of the day, we had a role-play in front of a TV camera; I found it nerve wracking when the journalist challenged my answers, it was a similar sensation to a viva exam! While it is unlikely that early within your career you will face the media, it's an additional skill that might become useful further along as you accept responsibilities within the healthcare system. This media training certainly changed the way I listen to and watch interviews.

Being a Specialty Registrar, you attend many courses and conferences relevant to your specialty; however, the Clinical Senate exposed me to a wider view of healthcare, leadership and management- I would have never expected to be attending an international conference in Leadership and Management. As I was presenting a poster, and being the co-author of a second one, the Clinical Senate funded my attendance to the Leaders in Healthcare Conference. This twoday event opened a whole new world to me; listening to remarkable international speakers discussing about different healthcare systems, social and healthcare problems, 'just culture, workforce mental health and wellbeing, team building and many other topics. Being part of discussion tables with other healthcare professionals from all over the world gives you further awareness of health inequalities and the current global situation in health and social care. Events like these, regularly attending Senate Council Meetings and participating in projects with Public Health, broaden my perspective on patient care and service provision. Having been exposed to the wider aspect of healthcare systems, allows me to understand better service provision and the impact of financial implications within patient care. This insight has become particularly useful when leading on projects such as a Palliative Dentistry document as part of my involvement with the Management Clinical Network for Special Care Dentistry in the Midlands. At a local level, since my Fellowship finished, I have also been invited to Health and Social Care Professional Local Groups where I shared my findings and opinions in topics such as Mental Health and Physical Activity. My experience writing clinical and non-clinical reports has become an asset within my Service when actively supporting to rebuild dental services during the Covid-19 outbreak.

Combining my specialty training and my Clinical Senate fellowship was challenging at times; I needed to be as organised as ever to ensure that I did not miss any clinical time but neither important Senate meetings. However, I feel very privileged to have been exposed to areas of leadership and management that other colleagues do not experience until much further in their careers. Previously, leadership and management skills would have been brought by your own experience having a long career in the healthcare system. However, within the last few years, there are lots of opportunities to explore those non-clinical aspects earlier within your career (e.g. Dental Clinical Fellowships, The Darzi Fellowship). Along your career you will come across many opportunities to enhance your knowledge and clinical skills. However, I would also encourage you to widen your horizons and explore non-clinical learning; your patients and colleagues will benefit from your broad experience but also it will enhance your satisfaction and future job opportunities.

Elizabeth Gonzalez-Malaga 